\title{
Cellulose Associated with Pet Bottle Waste in Cement Based Composites
}

\author{
Camila Laís Farrapo ${ }^{a *}$, Camila Soares Fonseca ${ }^{b}$, Tamires Galvão Tavares Pereira ${ }^{a}$,
}

Gustavo Henrique Denzin Tonoli ${ }^{a}$, Holmer Savastano Juniorc, Rafael Farinassi Mendes ${ }^{b}$

\author{
${ }^{a}$ Departamento de Ciencias Florestais, Universidade Federal de Lavras, 3037, Lavras, MG, Brasil. \\ ${ }^{b}$ Departamento de Engenharia, Universidade Federal de Lavras, 3037, Lavras, MG, Brasil. \\ ${ }^{c}$ Faculdade de Zootecnia e Engenharia de Alimentos, Universidade de São Paulo, 23, Pirassununga, SP, \\ Brasil.
}

Received: February 08, 2017; Revised: June 07, 2017; Accepted: June 12, 2017

\begin{abstract}
The present study was to evaluate the effect of polyethylene terephthalate (PET) particle sizes on the mechanical and physical properties of extruded fiber-cement composites with different particle sizes combined to cellulose pulp in the production of fiber cement by the extrusion process. The design consisted of four formulations, one composed of $5 \%$ cellulose and the other three with $2.5 \%$ cellulosic pulp and $2.5 \%$ of PET particles with different particle sizes. Physical, mechanical and microstructural tests were performed without aging cycles and after 200 and 400 accelerated aging cycles. The degradation of vegetable fibers in the cement and the decrease of properties with aging was observed. PET particles were more resistant in alkaline environment and did not degrade. However, particle size did not exert great effect in the physical and mechanical properties of the composite. Thus, the use of PET particles shows potential as a reinforcement for fiber-cement composites.
\end{abstract}

Keywords: Composites, cellulose, accelerated aging, particle size, extrusion.

\section{Introduction}

Cement based composites are normally brittle, feature low tensile strength, low ductility, and low tenacity. One way to improve these requirements is to add small fractions of fibers, which range from $0.5 \%$ to $5 \%$ of volume during mixing ${ }^{1}$.

The incorporation of fibers is widely used to improve tensile and flexural strength of concrete and mortar, further allowing a reduction in cracking by retraction at an early age, restricting the spread of cracks in cement, thereby increasing resistance to the entry of aggressive agents, with a resultant increase in the durability of the structure ${ }^{2,3}$.

Conventionally, the material used as reinforcement in fiber-cement is asbestos; however, due to the worldwide tendency of reviewing the use of this mineral fiber, various studies have been conducted regarding the incorporation of different types of fibers in cementitious composites, including vegetable fibers, agribusiness waste and even recycled polymers ${ }^{3-9}$.

The use of vegetable fibers as a reinforcement in fibercement composites leads to a set of advantages, such as wide availability, low cost, besides being a material that is renewable and not harmful to health. However, long-term durability of fiber-cements reinforced with lignocellulosic material is problematic due to the degradation of vegetable fibers in alkaline environment, which leads to loss of reduction in toughness and maximum strength, of the composite after accelerated wetting and drying cycles, that simulates the conditions of use ${ }^{10-15}$.

*e-mail: camila.farrapo@dcf.ufla.br
To circumvent this problem, one of the evaluated alternatives is the insertion of polymeric fibers by themselves or in combination with vegetable fibers in cementitious composites ${ }^{16-20}$. The addition of synthetic fibers confers excellent physical and mechanical properties to the fibercement composites, because improvement better tensile performance and strength. Synthetic fibers are less sensitive to alkali attack and possess good mechanical properties, resulting in composites with better performance in the longterm $^{18}$. However, besides not being derived from renewable sources, polymeric fibers can increase the final cost of the material by up to $40 \%{ }^{21}$. Currently, the Brazilian industry uses a mixture of fibers derived from Eucalyptus cellulosic pulp with polymeric fibers, mainly Vinyl polyacetate (PVA) and polypropylene $\mathrm{e}^{20-22}$.

Solid waste generated in urban centers, like packaging and food waste, is one of the most prominent environmental topics in discussions about the environment. Some studies have focused on the generation, collection, disposal, and recycling of these materials ${ }^{23}$. Polymeric waste from packaging, in particular, poses a great challenge in regards to its destination after consumption. Due to its excellent characteristics, clarity, light weight, and selective gas permeability, the consumption of polyethylene terephthalate (PET) in the form of bottles has been significantly increasing and, as it takes approximately 180 years to decompose in nature, the cumulative amount of this waste has been drastically growing ${ }^{24,25}$. Data from the National Association for PET Container (NAPCOR) shows that in 2014 in the USA, the number of PET containers available for recycling was 2.65 million tons; however, 0.82 
million tons were recycled, in other words, only $31 \%$ of the waste $^{26,27}$. In Brazil, it is estimated that PET is about $20 \%$ of solid urban waste ${ }^{28}$ and in 2015 only $51 \%$ of Brazilian PET was recycled according to Associação Brasileira da Indústria do PET (ABIPET) ${ }^{29}$.

Several studies have been conducted with the insertion of PET bottle waste in concrete and have provided satisfactory results in flexural tests, showed that the concretes containing PET achieved a higher peak load, but results obtain without aging. However, these studies reveal that the durability of the material is affected over time due to PET degradation in alkaline environment ${ }^{3,30-32}$. Combined with this fact, there is no studies in literature that describe the insertion of PET particles for reinforcement of fiber-cements produced by the extrusion process, which is continuous process that consists of forcing the passage of a pseudoplastic mixture through an opening that sets the form of the final product ${ }^{33}$. Therefore, the objective of this study was to evaluate the effect of PET particle sizes on the mechanical and physical properties of extruded fiber-cement composites.

\section{Materials and Methods}

\subsection{Raw material}

As a reinforcement of the cementitious matrix, cellulosic pulp bleached (fiber with $0,8 \mathrm{~mm}$ ) and polyethylene terephthalate (PET) bottle waste were used. Commercial Eucalyptus cellulosic pulp (Eucalyptus urograndis) with an approximate age of 7 years (Jacareí, SP, Brazil). PET bottles were ground and sieved with three different particle sizes: PET 1 (between 20 and 24 mesh sieves), PET 2 (between 24 and 32 mesh sieves) and PET 3 (between 32 and 35 mesh sieves).

\subsection{Constituents of the cementitious matrix}

Ordinary Portland cement (OPC) correspondent to type I (ASTM-C150) and ground agricultural limestone, were used as cementitious matrix. Limestone was incorporated as a partial replacement of Portland cement with the objective of reducing the production costs of fiber cement ${ }^{34}$. The additives added during the process -Hydroxypropyl Methylcellulose (HPMC) and carboxylic polyether (ADVA) - have the purpose of facilitating the extrusion, ensuring the pseudoplastic behavior of the mixture.

\subsection{Fiber-cement production}

Cellulosic pulp was dispersed in water by mechanical stirring in a mixer and was insert wet $(0.43 \mathrm{~g} / \mathrm{mL})$ in matrix. Fiber-cement composites with different particle sizes of PET waste, in association with the dispersed cellulose pulp, were produced in laboratory scale by extrusion process. The formulations used in the production of the composites were based on previous studies ${ }^{2}$. The percentages of reinforcement materials for each formulation can be verified in Table 1 .
Table 1. Formulation of fiber cement composites.

\begin{tabular}{cccc}
\hline \multirow{2}{*}{ Formulation } & Pulp & PET & PET Particle Size \\
\cline { 2 - 4 } & \multicolumn{2}{c}{$\%$} & Mesh \\
\hline PET 0 & 5 & 0 & ------- \\
PET 1 & 2.5 & 2.5 & $20-24$ \\
PET 2 & 2.5 & 2.5 & $24-32$ \\
PET 3 & 2.5 & 2.5 & $32-35$ \\
\hline
\end{tabular}

All formulations used 65\% Portland CPV-ARI cement, $30 \%$ agricultural limestone and 5\% reinforcing fiber, considering that $1 \%$ of each additive (ADVA and HPMC) was added in relation to the cement, and the water-cement ratio used was around $30 \%$. The mixture of all materials took place in a planetary mixer. First, the cement, limestone and HPMC were mixed at a rotation of $140 \mathrm{rpm}$ for 2 minutes; next, the cellulose pulp, PET, ADVA, and water were added, remaining at a rotation of $285 \mathrm{rpm}$ for another $5 \mathrm{~min}$ in order to promote the homogeneous distribution of the cellulosic pulp in the formed mixture.

The cementitious paste formed was processed in a helical extruder, Verdés brand, model 051, with screw speed of approximately $25 \mathrm{rpm}$. After the test specimens were produced, they were stored for three days in saturated environment. The complete curing of the material took place for seven days in a vaporization chamber at $70^{\circ} \mathrm{C}$.

\subsection{Accelerated aging cycles}

The mechanical, physical and microstructural properties of the composites were analyzed in samples without aging and with accelerated aging cycles. The wet-dry accelerated aging simulates composite aging under the effects of the weather. For such treatment, an accelerated aging chamber was used through wet-drying. The samples were submerged in water for $170 \mathrm{~min}$. Upon being removed from the water, they were heated up to $70^{\circ} \mathrm{C}$ for drying for the same length of time. All formulations went through 200 and 400 cycles of this accelerated aging.

\subsection{Mechanical, physical and microstructural characterization of composites}

The mechanical test was performed using the universal machine, Arotec brand, equipped with a $20 \mathrm{kN}$ load cell. The bending test was performed to establish the modulus of rupture (MOR), modulus of elasticity (MOE), and tenacity. This test was performed using 9 specimen repetitions, following the procedures described in RILEM ${ }^{35}$ and using a three-point bending configuration, gap of $150 \mathrm{~mm}$, and speed of $2 \mathrm{~mm} / \mathrm{min}$.

The physical properties were analyzed according to the ASTM C 948-81 standard ${ }^{36}$. Through this analysis, bulk density, water absorption and apparent porosity were obtained. For each formulation, nine test specimens were analyzed. 
Scanning electron microscopy (SEM) was applied for the characterization of the fracture surface of the test specimens after flexural test. The objective of this evaluation was to check the interface of the cellulosic pulp and PET waste with the cementitious matrix before and after the aging cycles.

\subsection{Analysis of the results}

The results of this study were evaluated in a randomized design. The variance analysis and the Scott-Knott mean test were performed at $5 \%$ of significance.

\section{Results and Discussion}

\subsection{Physical properties of the composites}

Figure 1 shows the average and standard deviation values of the bulk density of the composites without aging and after 200 and 400 cycles of accelerated aging. It can be observed that the composites produced with fine (PET 3- 32 to 35 mesh) and medium (PET 2- 24 to 32 mesh) PET displayed greater density soon after curing. This fact can be justified as the increase in PET particle size (PET 1- 20 to 24 mesh) may generate an increase in void spaces due to interlacing at the time of extrusion, whereas smaller particle sizes ease the filling of void spaces in the matrix, resulting in greater compaction and higher density values ${ }^{2}$. The low density observed for the composites produced only with cellulose is due to the lower density of the reinforcement material, since the density of PET bottle particles found in literature by Mancini et al. ${ }^{37}$ is close to $1.345 \mathrm{~g} / \mathrm{cm}^{3}$ and the density of cellulosic pulp varies from 0.50 to $0.65 \mathrm{~g} / \mathrm{cm}^{338}$.

After the accelerated aging cycles, all formulations displayed increased bulk density; this fact is related to the hydration of the cementitious matrix that takes place over exposition to water and natural carbonation during the aging

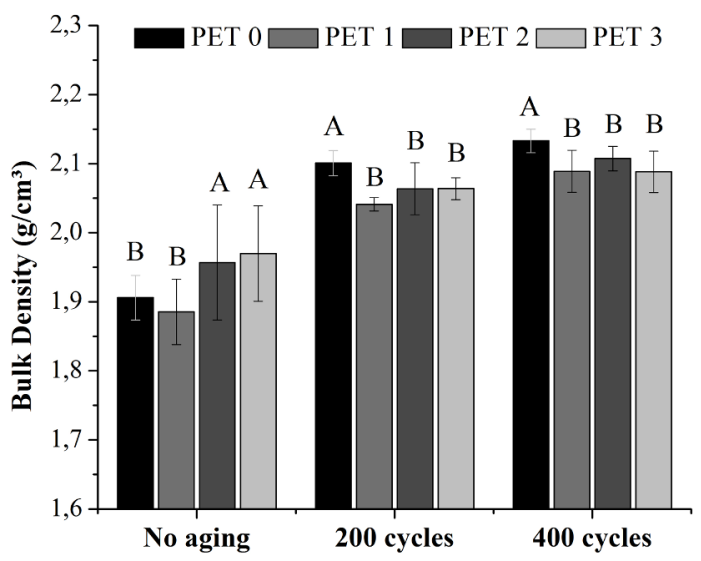

Figure 1. Average and standard deviation values of bulk density of fiber-cement composites produced with PET particles. Consecutive means of the same letter do not statistically differ by the Scott-Knott mean test, at $5 \%$ of significance. PET1 $=20$ to 24 mesh, PET2 $=24$ to 32 mesh and PET3 = 32 to 35 mesh. cycles, as Portland cement is a hydraulic binder consisting of silicate and calcium aluminates. The continuous availability of water that takes place with aging favors the development of silicate hydrates and calcium aluminates, benefiting the densification of the cementitious material ${ }^{39-41}$. Almeida et al. ${ }^{13}$, upon evaluating fiber-cement reinforced with cellulose pulp, reported improvement of mechanical properties of the composites and associated this characteristic to the increased density. In this study, the authors described values of 1.52 $\mathrm{g} / \mathrm{cm}^{3}, 1.56 \mathrm{~g} / \mathrm{cm}^{3}$ and $1.58 \mathrm{~g} / \mathrm{cm}^{3}$ for composites evaluated without aging, after 200 and 400 cycles of accelerated aging, respectively. Teixeira et al..$^{42}$, upon evaluating fiber-cement reinforced with cellulose and polypropylene in concentrations of $4 \%$ and $2 \%$ respectively, found density values equal to $1.42 \mathrm{~g} / \mathrm{cm}^{3}$ for samples without aging and $1.67 \mathrm{~g} / \mathrm{cm}^{3}$ for samples tested after 50 cycles of accelerated aging.

However, it was observed that after both aging cycles, bulk density was higher for composites produced only with cellulosic pulp as, with aging, the ions from the hydration phases of the cement re-precipitate in the lumen and in the cellular wall of vegetable fibers. Therefore, the structures degrade due to the breakdown of intermolecular links, what is called fiber mineralization ${ }^{11,12}$. This phenomenon, taking place after aging, leads to a decrease in void spaces of the composites containing cellulose fibers, consequently decreasing water absorption, as can be seen in Figure 2, and it is related to the decrease of the porosity of the composite (Figure 3).

Water absorption is an important property of composites reinforced with vegetable fibers, since it evaluates their potential for external environments applications. High water absorption by fibers may result in a reduction of mechanical properties, high dimensional changes and reducing the durability of composites ${ }^{43}$. No statistical difference was verified between water absorption of the composites with different PET particle sizes, both before aging and after 200

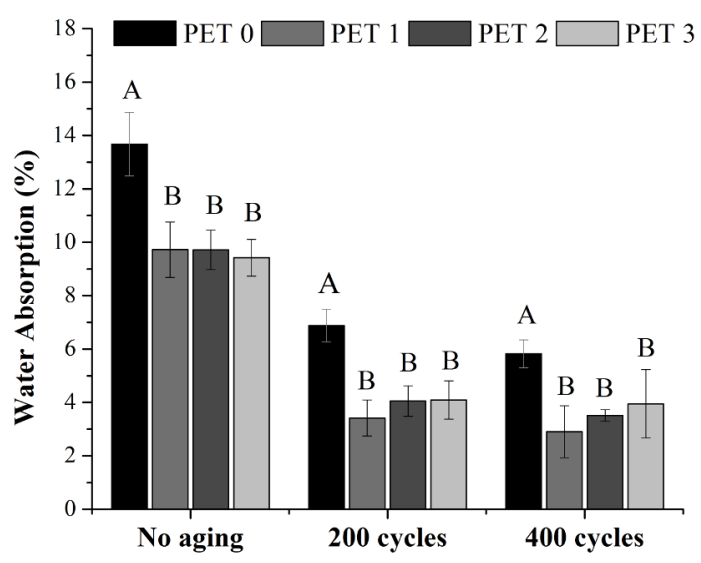

Figure 2. Average and standard deviation values of water absorption of fiber cement produced with PET particles. Consecutive means of the same letter do not statistically differ by the Scott-Knott mean test, at $5 \%$ of significance. PET1 $=20$ to 24 mesh, PET2= 24 to 32 mesh and PET3 $=32$ to 35 mesh. 


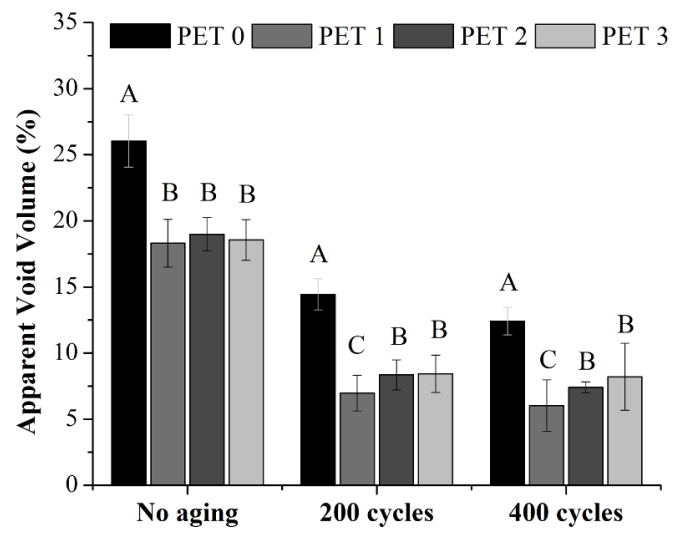

Figure 3. Average and standard deviation values of apparent porosity of fiber-cement produced with PET particles. Consecutive means of the same letter do not statistically differ by the Scott-Knott mean test, at $5 \%$ of significance. PET1 $=20$ to 24 mesh, PET2 $=24$ to 32 mesh and PET3 $=32$ to 35 mesh.

and 400 accelerated aging cycles. The composite produced only with cellulosic pulp obtained the highest absorption value, which is justified since vegetable fibers are porous and hydrophilic, resulting in higher water absorption when compared to polymeric particles.

The NBR 12800 standard $^{44}$ establishes that the maximum water absorption acceptable for corrugated roofing sheets made of fiber cement without asbestos should be $37 \%$. In the data observed in all situations, water absorption displayed by the composites in this study can be considered satisfactory, since it did not exceed the maximum required by the standard.

After curing, there was no statistical difference between composites with different PET particle sizes. The composite reinforced only with cellulosic pulp obtained the higher apparent porosity value before and after accelerated aging cycles. Moreover, it was possible to observe that the higher the PET particle size, the lower the apparent porosity after aging. This can be explained by the fact that these particles feature greater voids between themselves, easing the filling with hydration products of cement, as well as smaller particle sizes may suffer greater degradation with the alkalinity of the cement due to the higher area of contact of PET 3 particles.

Pelisser et al. ${ }^{32}$ reported lower porosity in cementitious composites reinforced with PET when compared to composites without PET after 150 days of aging. However, after 365 days, the authors reported higher porosity due to the slow degradation of polymeric particles. Such fact was not observed in this work for larger particles, since PET1 particles were kept in alkaline matrix even after 400 cycles of accelerated aging, as can be seen in Figure 4.

As happened with the values of water absorption, the reduction of apparent porosity and the increase in bulk density in composites reinforced only with cellulose, observed after accelerated aging cycles, is related to the mineralization and degradation of vegetable fibers in a highly alkaline environment, as can be seen in Figure 5. It is possible to notice that before aging (Figure 5A) the amount of fiber dispersed in the matrix is higher than after 400 cycles of accelerated aging (Figure 5B).

Almeida et al. ${ }^{13}$, studying fiber-cement reinforced with cellulosic pulp, observed a reduction in apparent porosity of close to $31 \%, 28 \%$ and $23 \%$ for those samples evaluated without aging, after 200 and 400 cycles of accelerated aging. Teixeira et al. ${ }^{42}$, upon evaluating fiber-cement reinforced with cellulose and polypropylene in concentrations of 4 and $2 \%$, respectively, found the respective values of $23.3 \%$ and $33.0 \%$ for water absorption. For apparent porosity in the samples evaluated before accelerated aging and after 50 cycles, the values decreased to $21.5 \%$ and $30.9 \%$ respectively. Other authors have also reported that, after cycles of accelerated aging, there is a decrease in water absorption and apparent porosity, as well as an increase in bulk density ${ }^{2,20,45}$.

\subsection{Mechanical properties of the composites}

Upon analyzing the results obtained for MOR (Figure 6), it can be observed that there has been a significant difference between composite formulations without aging and after 200 cycles of aging, which showed higher values. This increase of MOR found after 200 cycles can be related to an incomplete curing of composites after seven days in the vaporization chamber, causing the fiber cement to continue curing during the beginning of accelerated aging. This fact was also reported by Pelisser et al..$^{32}$ that, upon studying the mechanical properties of concrete produced with PET fibers with average diameter of $25-30 \mathrm{~mm}$, found values of MOR between 3.75 and $4.47 \mathrm{MPa}$ after curing and between 4.48 and $4.67 \mathrm{MPa}$ after 150 days of aging.

After 400 cycles, the values of MOR have a downward tendency and all formulations have shown to be statistically equal between themselves, showing that over time the use of PET bottle particles associated to cellulose confers the same performance when compared to cellulosic pulp in fibercement. It is possible to observe that after 200 cycles of aging, the formulation using only cellulose pulp as reinforcement presented the highest values (Figure 6). After 400 cycles, it is the one that presented the lowest value. According to Teixeira $^{42}$, the value of MOR is related to the interaction and distribution of tensions between the fiber and the matrix, in addition to tensile strength during flexure. Thus, it can be concluded that after the most severe aging ( 400 cycles), there was greater degradation of cellulosic fiber due to the mineralization of the vegetable material, when compared to PET particles, as it was observed in Figures 4 and 5, causing the cellulosic fiber to lose its capacity to distribute the stress and, consequently, displaying less resistance to fracture. Teixeira et al. ${ }^{42}$, upon evaluating fiber-cement roofing sheets reinforced with $2 \%$ polypropylene combined with $4 \%$ cellulose, found higher values in the order of $40 \%$ when compared to composites reinforced with $6 \%$ cellulose. 

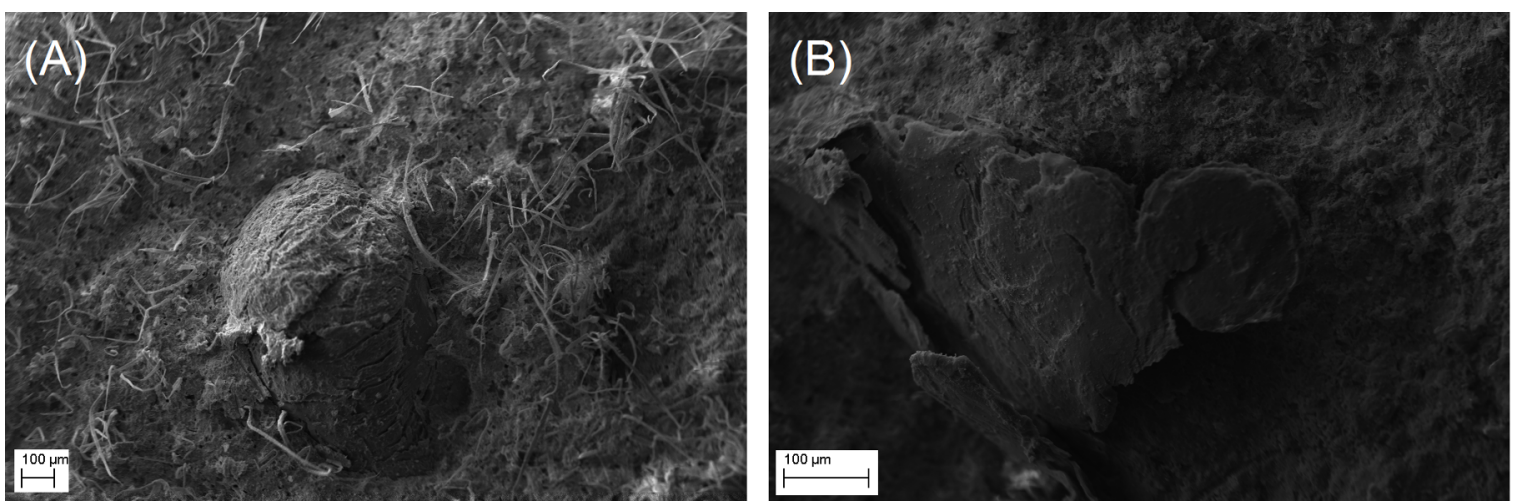

Figure 4. Scanning electron microscopy (SEM) micrographs of the surface of fracture of test specimens reinforced with $2.5 \%$ cellulosic pulp and 2.5\% PET1(20 to 24 mesh): (A) without aging (B) after 400 cycles of accelerated aging.
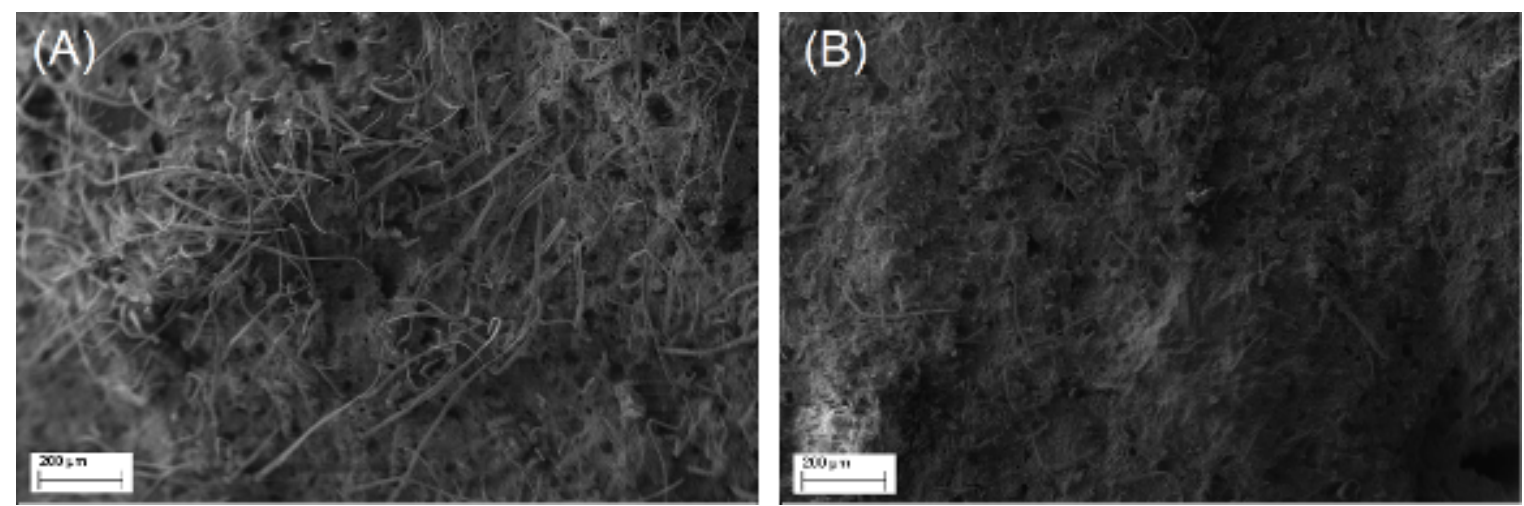

Figure 5. Scanning electron microscopy (SEM) micrographs of the surface of fracture of test specimens reinforced with $5 \%$ cellulosic pulp: (A) without aging (B) after 400 cycles of accelerated aging.

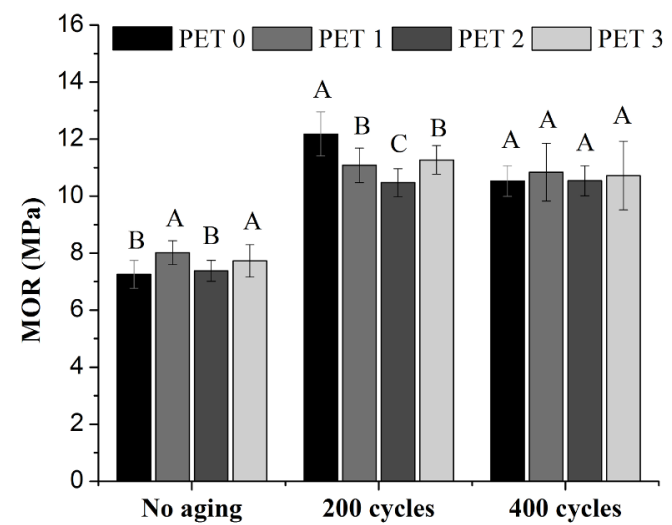

Figure 6. Average and standard deviation values of modulus of rupture of fiber-cement composites with PET particles. Consecutive means of the same letter do not statistically differ by the Scott-Knott mean test, at $5 \%$ of significance. PET $1=20$ to 24 mesh, PET $2=24$ to 32 mesh and PET3 $=32$ to 35 mesh.

The authors attribute this to the lower degradation of the polymeric fiber in alkaline environment, even after 50 cycles of accelerated aging. Almeida et al. ${ }^{13}$, upon evaluating fiber cement reinforced with cellulosic pulp produced by the extrusion process, reported an increase of MOR in the order of $5 \mathrm{MPa}$ to $10 \mathrm{MPa}$ for samples tested without aging and after 400 cycles of accelerated aging. Alamshahi et al. ${ }^{46}$ found values ranging from 8.09 to $11.03 \mathrm{MPa}$ for cement composite reinforced with polypropylene in the order of 2.16 to $4.28 \%$ combined with cotton and viscose fiber. In the same study, the authors found values of 6.25 to 7.35 MPa for fiber-cements reinforced with polyester in the same conditions. The authors attributed those lower values to the poor dispersion of polyester fibers in the cementitious matrix.

The NBR 15498 standard $^{47}$ for cementitious flat plate without asbestos sets values of MOR in regards to flexure, for plates tested in saturated state, of $4 \mathrm{MPa}$ for category 2, of $7 \mathrm{MPa}$ for category 3 and of $13 \mathrm{MPa}$ for category 4 . According to this standard, the cementitious composites produced are in category 3 , not varying category according to the formulation.

For MOE values (Figure 7), no significant difference was observed between the formulations without aging, but after 200 and 400 cycles of accelerated aging, composites reinforced only with cellulose showed lower values and were statistically different from the others. There was no significativedifferences among them, demonstrating that PET particle size did not exert influence on this property. However, this increase of MOE with the insertion of synthetic 


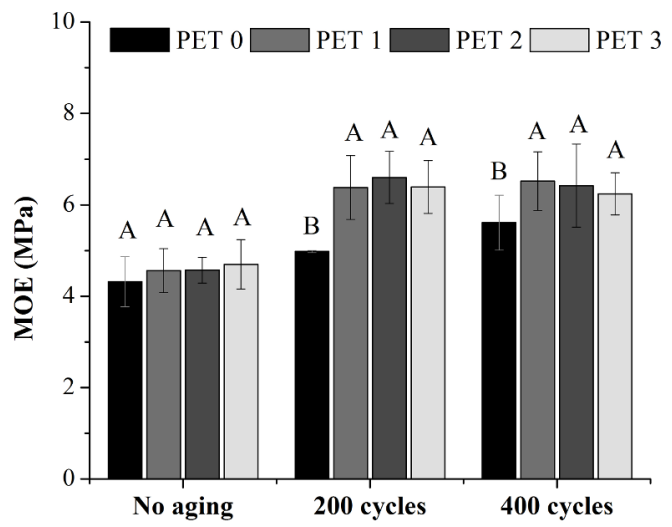

Figure 7. Average and standard deviation values of modulus of elasticity of fiber cement produced with PET particles. Consecutive means of the same letter do not statistically differ by the Scott-Knott mean test, at $5 \%$ of significance. PET $1=20$ to 24 mesh, PET2 $=24$ to 32 mesh and PET3 $=32$ to 35 mesh.

particles after aging may be related to the lower degradation of PET particles in alkaline environment when compared to cellulose ${ }^{42}$.

Pelisser et al. ${ }^{26}$, studying the mechanical properties of concrete reinforced with PET fibers varying from 0.0 to $0.3 \%$ of composite volume, found that the degradation of polymeric fibers in the cementitious matrix is slow, with no differences after 28 and 150 days. Koo et al.$^{48}$, upon evaluating the insertion of recycled PET particles in concrete, concluded that the variation in relation to the control samples was very low, remaining within an acceptable margin, between 23 and $25 \mathrm{GPa}$, being insignificant for the results when only considering elements of civil construction.

Upon analyzing the results obtained for the specific energy of cementitious composites and the typical stress vs. strain curves (Figure 8 and Figure 9, respectively), it is observed that energy absorption was higher for the formulation with $100 \%$ cellulosic pulp in the three conditions analyzed. This behavior may be related to the structure of the PET particle, which is more rigid than cellulosic pulp ${ }^{32,22,49,50}$. Furthermore, the geometry of vegetable fibers, which have a higher slenderness index than PET particles, may have influenced the improved dissipation of energy within the composite during the flexural test, increasing the specific energy of the fiber-cement reinforced with cellulose ${ }^{13}$.

Moreover, it was observed that right after curing, the fiber-cement reinforced with larger particle sizes obtained better results, followed by the average particles and, finally, the worst result was presented by the smaller particles. However, after the aging cycles, the association of the three particle sizes with cellulosic pulp used in these studies was similar to each other. However, after 400 cycles of aging, it is possible to see that the formulation composed of larger particles (PET 1) was more resistant to deformation when exposed to the same load than the compositions with smaller

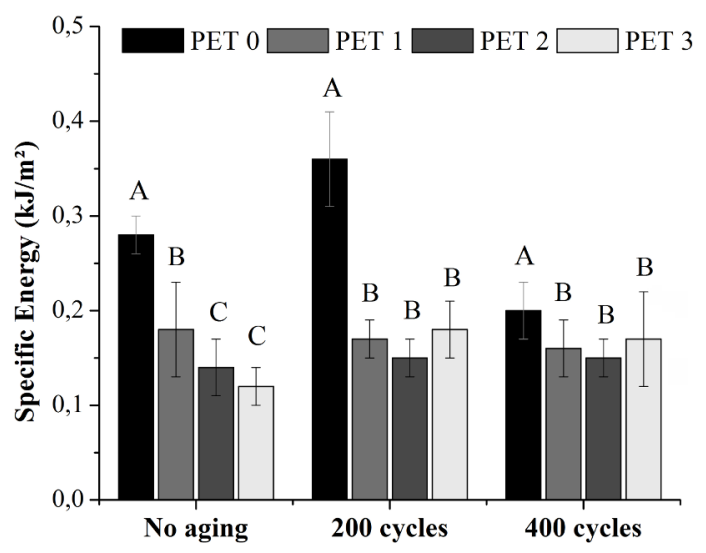

Figure 8. Average and standard deviation values of specific energy of fiber cement produced with PET particles. Consecutive means of the same letter do not statistically differ by the Scott-Knott mean test, at $5 \%$ of significance. PET $1=20$ to 24 mesh, PET2 $=24$ to 32 mesh and PET3 $=32$ to 35 mesh.
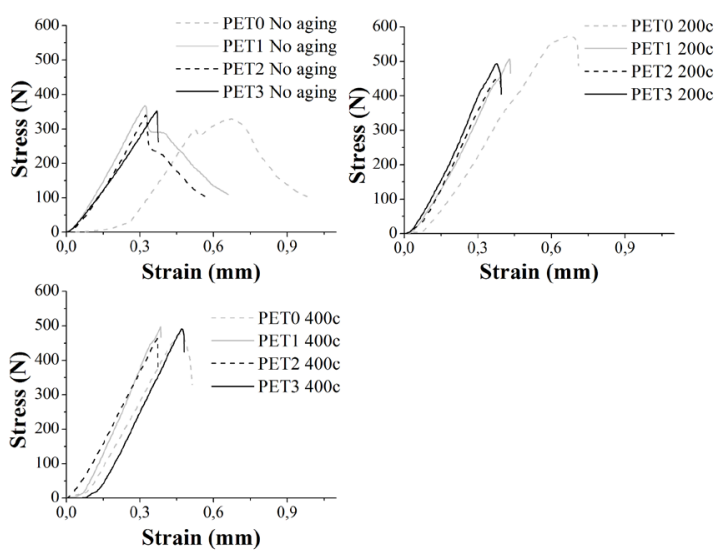

Figure 9. Typical stress vs. strain curves of composites at (a) no aging; (b) after 200 accelerated aging cycles; (c) 400 accelerated aging cycles.

particles (PET 3) and that fiber cement composed only of cellulose (PET 0). In general, the tenacity of composites reinforced with PET did not show considerable changes after the aging cycles, what can be related to the slow degradation and maintenance of these polymeric particles in the matrix, as it was previously discussed (Figure 4) ${ }^{32}$. Thus, the association of PET particles with cellulosic pulp was efficient in the maintenance of specific energy even after the most severe aging cycles ( 400 cycles).

However, the observed increase in specific energy for fiber-cements reinforced only with cellulose after 200 aging cycles may be related to the incomplete curing of the cement in a vaporization chamber for seven days. Furthermore, for this formulation, the specific energy decreased considerably after 400 aging cycles. This reduction may be related to the increase in MOE of the matrix-reinforcement interface, which is the result of the densification of the material resulting from 
the re-precipitation of the hydration products of cement that are deposited in the lumen of cellulosic fibers, resulting in the degradation of vegetable material in a highly aggressive environment, causing it to lose its reinforcement capacity ${ }^{10-13,20}$.

The association of cellulosic pulp with PET bottle particles did not cause variation in MOR values after the most aggressive aging conditions (400 cycles). However, for MOE, the insertion of polymeric particles exerted a positive effect, and for specific energy, the presence of cellulosic pulp in the mixed composites was effective for the maintenance of energy absorption after 400 accelerated aging cycles due to the format of cellulose pulp fibers, which favor the absorption of energy during their slipping.

\section{Conclusions}

In general, composites reinforced only with cellulosic pulp presenter the higher mechanical performance without aging. However, after accelerated aging cycles, the formulations containing PET particles in their constitution obtained better results, as these polymeric particles degrade more slowly in alkaline environment in relation to cellulose. For the physical properties, all formulations showed the same tendency of decreasing water absorption and apparent porosity, as well as an increase in bulk density after accelerated aging cycles. The particle size of PET particles did not exert a significant effect on the mechanical properties of the composites, before and after cycles of accelerated aging. After aging, fiber-cement composites reinforced with coarser PET particles presented lower density, while the apparent porosity was reduced with the increase in particle size. This way, the insertion of PET bottle particles shows potential to be used as reinforcement in cement based materials.

\section{References}

1. Wang Y, Wu HC, Li VC. Concrete Reinforcement with Recycled Fibers. Journal of Materials in Civil Engineering 2000;12(4):314-319.

2. Tonoli GHD, Savastano Jr. H, Fuente H, Negro C, Blanco A, Lahr FAR. Eucalyptus pulp fibres as alternative reinforcement to engineered cement based composites. Industrial Crops and Products 2010;31(2):225-232.

3. Borg RP, Baldacchino O, Ferrara L. Early age performance and mechanical characteristics of recycled PET fibre reinforced concrete. Construction and Building Materials 2016;108:29-47.

4. Ochi T, Okubo S, Fukui K. Development of recycled PET fiber and its applications as concrete-reinforcing fiber. Cement and Concrete Composites2007;29(6):448-455.

5. Andrade Silva F, Chawla N, Toledo Filho RD. Tensile behavior of high performance natural (sisal) fibers. Composites Science and Technology2008;68(15-16):3438-3443.

6. Andrade Silva F, Chawla N, Toledo Filho RD. Mechanical Behaviour of Natural Sisal Fibers. Journal of Biobased Materials and Bioenergy2010;4:1-8.
7. Tonoli GHD, Santos SF, Joaquim AP, Savastano Jr. H. Effect of accelerated carbonation on cementitious roofing tiles reinforced with lignocellulosic fibre. Construction and Building Materials2010;24(2):193-201.

8. Karade SR. Cement-bonded composites from lignocellulosic wastes. Construction and Building Materials 2010;24(8):1323-1330.

9. Khorami M, Ganjian E, Srivastav A. Feasibility Study on Production of Fiber Cement Board Using Waste Kraft Pulp in Corporation with Polypropylene and Acrylic Fibers. Materials Today 2016;3(2):376-380.

10. Coutts RSP. A review of Australian research into natural fiber cement composites. Cement and Concrete Composites 2005;27(5):518-526.

11. Mohr BJ, Nanko H, Kurtis KE. Durability of kraft pulp fibercement composites to wet/dry cycling. Cement and Concrete Composites2005;27(4):435-448.

12. Tonoli GHD, Santos SF, Savastano Jr. H, Delvasto S, Mejía de Gutiérrez R, Lopez de Murphy MM. Effects of natural weathering on microstructure and mineral composition of cementitious roofing tiles reinforced with fique fiber. Cement and Concrete Composites2011;33(2):225-232.

13. Almeida AEFS, Tonoli GHD, Santos SF, Savastano Jr. H. Improved durability of vegetable fiber reinforced cement composite subject to accelerated carbonation at early age. Cement and Concrete Composites 2013;42:49-58.

14. Mohr BJ, Nanko H, Kurtis KE. Durability of thermomechanical pulp fiber-cement composites to wet/dry cycling. Cement and Concrete Research2005;35(8):1646-1649.

15. Kim PJ, Wu HC, Lin Z, Li VC, de Lhoneux D, Akers SAS. Micromechanics-based durability study of cellulose cement in flexure. Cement and Concrete Research 1999;29(2):201-208.

16. Negro C, Blanco A, Fuente E, Sánchez LM, Tijero J. Influence of flocculant molecular weight and anionic charge on flocculation behaviour and on the manufacture of fibre cement composites by the Hatschek process. Cement and Concrete Research 2005;35(11):2095-2103.

17. Liu X, Ye G, De Schutter G, Yuan Y, Taerwe L. On the mechanism of polypropylene fibres in preventing fire spalling in self-compacting and high-performance cement paste. Cement and Concrete Research2008;38(4):487-499.

18. Ahmed SFU, Mihashi H. Strain hardening behavior of lightweight hybrid polyvinyl alcohol (PVA) fiber reinforced cement composites. Materials and Structures 2011;44(6):1179-1191.

19. Hu W, Yang XG, Zhou JW, Xing HG, Xiang J. Experimental Research on the Mechanical Properties of PVA Fiber Reinforced Concrete. Research Journal of Applied Sciences, Engineering and Technology 2013;5(18):4563-4567.

20. Pizzol VD, Mendes LM, Savastano Jr. H, Frías M, Davila FJ, Cincotto MA, et al. Mineralogical and microstructural changes promoted by accelerated carbonation and ageing cycles of hybrid fiber-cement composites. Construction and Building Materials 2014;68:750-756.

21. Dias CMR, Savastano Jr. H, John VM. Exploring the potential of functionally graded materials concept for the development of fiber cement. Construction and Building Materials 2010;24(2):140146. 
22. Corinaldesi V, Nardinocchi A. Influence of type of fibers on the properties of high performance cement-based composites. Construction and BuildingMaterials 2016;107:321-331.

23. Berthier HC. Garbage, work and society. Resources, Conservation and Recycling2003;39(3):193-210.

24. Mendoza-Carrasco R, Cuerda-Correa EM, Alexandre-Franco MF, Fernández-González C, Gómez-Serrano V. Preparation of high-quality activated carbon from polyethyleneterephthalate (PET) bottle waste. Its use in the removal of pollutants in aqueous solution. Journal of Environmental Management2016;181:522-535.

25. Pimpan V, Sirisook R, Chuayjuljit S. Synthesis of unsaturated polyester resin from postconsumer PET bottles: Effect of type of glycol on characteristics of unsaturated polyester resin. Journal of Applied Polymer Science2003;88(3):788-792.

26. Nikbin IM, Rahimi RS, Allahyari H, Fallah F. Feasibility study of waste Poly Ethylene Terephthalate (PET) particles as aggregate replacement for acid erosion of sustainable structural normal and lightweight concrete. Journal of Cleaner Production 2016;126:108-117.

27. National Association for PET Container Resources (NAPCOR). Report on Postconsumer PET Container Recycling Activity in 2014Florence: NAPCOR; 2015.

28. Spinacé MAS, De Paoli MA. A tecnologia da reciclagem de polímeros. Química Nova 2005;28(1):65-72.

29. Associação Brasileira da Indústria do PET (ABIPET). Décimo Censo da Reciclagem do PET no BrasilSão Paulo: ABIPET; 2016.

30. Won JP, Jang CI, Lee SW, Lee SJ, Kim HY. Long-term performance of recycled PET fibre-reinforced cement composites. Construction and Building Materials2010;24(5):660-665.

31. Foti D. Use of recycled waste pet bottles fibers for the reinforcement of concrete. Composite Structures 2013;96:396-404.

32. Pelisser F, Montedo ORK, Gleize PJP, Roman HR. Mechanical properties of recycled PET fibers in concrete. Materials Research2012;15(4):679-686.

33. Teixeira RS, Tonoli GHD, Santos SF, Fiorelli J, Savastano Jr. H, Rocco Lahr FA. Extruded Cement Based Composites Reinforced With Sugar Cane Bagasse Fibres. Key Engineering Materials 2012;517:450-457.

34. Bezerra EM, Joaquim AP, Savastano Jr. H, John VM, Agopyan V. The effect of different mineral additions and synthetic fiber contents on properties of cement based composites. Cement and Concrete Composites2006;28(6):555-563.

35. RILEM 49 TFR. Testing methods for fibre reinforced cementbased compositesParis: RILEM; 1984.

36. ASTM International. ASTM C 948-81: Test Method for Dry and Wet Bulk Density, Water Absorption, and Apparent Porosity of Thin Sections of Glass-Fiber Reinforced ConcreteWest Conshohocken: ASTM International; 2001.
37. Mancini SD, Bezerra MN, Zanin M. Reciclagem de PET Advindo de Garrafas de Refrigerante Pós-Consumo. Polímeros 1998;8(2):68-75.

38. Seca AML, Domingues FM. Densidade e rendimento em polpa celulósica e sua relação com alguns parâmetros químicos no eucalipto. Pesquisa Agropecuária Brasileira 2006;41(12):16871691.

39. Taylor HFW. Cement Chemistry. London: Academic Press; 1990.

40. Yang M, Neubauer CM, Jennings HM. Interparticle potential and sedimentation behavior of cement suspensions. Advanced Cement Based Materials 1997;5(1):1-7.

41. Nägele EW. The transient zeta potential of hydrating cement. Chemical Engineering Science 1989; 44(8):1637-1645.

42. Teixeira RS, Tonoli GHD, Santos SF, Savastano Jr. H, Protásio TP, Toro EF, et al. Different ageing conditions on cementitious roofing tiles reinforced with alternative vegetable and synthetic fibres. Materials and Structures2014;47(3):433-444

43. Mendes RF, Mendes LM, Oliveira JE, Savastano Jr. H, Glenn G, Tonoli GHD. Modification of eucalyptus pulp fiber using silane coupling agents with aliphatic side chains of different length. Polymer Engineering \& Science2015;55(6):1273-1280.

44. Associação Brasileira de Normas Técnicas (ABNT). NBR 12800: Telha de fibrocimento, tipo pequenas ondas Rio de Janeiro: ABNT; 1993.

45. Fonseca CS, Silva TF, Silva MF, Oliveira IRC, Mendes RF, Hein PRG, et al. Eucalyptus cellulose micro/nanofibrils in extruded fiber-cement composites. Cerne2016;22(1):59-68.

46. Alamshahi V, Taeb A, Ghaffarzadeh R, Rezaee MA. Effect of composition and length of $\mathrm{PP}$ and polyester fibres on mechanical properties of cement based composites. Construction and Building Materials2012;36:534-537.

47. Associação Brasileira de Normas Técnicas (ABNT). NBR 15498: Placa plana cimentícia sem amianto - Requisitos e métodos de ensaioRio de Janeiro: ABNT; 2007.

48. Koo BM, Kim JHJ, Kim SB, Mun S. Material and Structural Performance Evaluations of Hwangtoh Admixtures and Recycled PET Fiber-Added Eco-Friendly Concrete for CO2 Emission Reduction. Materials2014;7:5959-5981.

49. Kim SB, Yi NH, Kim HY, Kim JHJ, Song YC. Material and structural performance evaluation of recycled PET fiber reinforced concrete. Cement and Concrete Composites 2010;32(3):232240

50. Silva DA, Betioli AM, Gleize PJP, Roman HR, Gomes LA, Ribeiro JLD. Degradation of recycled PET fibers in Portland cement-based materials. Cement and Concrete Research 2005;35(9):1741-1746. 